\title{
Vitamin D serum levels in women using contraception containing drospirenone - a preliminary study
}

Michał Ciebiera ${ }^{1}$, Marta Włodarczyk², Aneta Słabuszewska-Jóźwiakk ${ }^{1}$, Magdalena Ciebiera ${ }^{3}$, Grażyna Nowicka², Grzegorz Jakiel ${ }^{1}$

\author{
${ }^{1}$ First Department of Obstetrics and Gynecology, Centre of Postgraduate Medical \\ Education, Warsaw, Poland \\ 2Department of Pharmacogenomics, Division of Biochemistry and Clinical Chemistry, \\ Medical University of Warsaw, Warsaw, Poland \\ ${ }^{3}$ Students' Scientific Association at the First Department of Obstetrics and \\ Gynecology, Medical University of Warsaw, Warsaw, Poland
}

Submitted: 1 November 2016

Accepted: 29 January 2017

Arch Med Sci 2019; 15, 2: 554-557

DOI: https://doi.org/10.5114/aoms.2017.70887

Copyright $\odot 2017$ Termedia \& Banach

Vitamin D is a group of steroid compounds soluble in fats. Vitamin D has powerful, pleiotropic effects all over the human body. It is synthesized in human skin, but can also be found in dietary supplements and fortified foods. Vitamin D receptors (VDR) can be found in many tissues, as well as in the female reproductive tract $[1,2]$. According to recent reports, it is believed that vitamin $D$ has a beneficial effect on lowering the risk of various diseases, e.g. multiple forms of cancer, diabetes, cardiovascular diseases, metabolic syndrome, multiple sclerosis, inflammatory bowel diseases and uterine fibroids [1-6]. Vitamin D regulates cell proliferation and differentiation, inhibits angiogenesis and stimulates apoptosis [1, 2, 4, 5]. Vitamin D levels are mostly measured using serum 25-hydroxyvitamin D $(25(\mathrm{OH}) \mathrm{D})$ concentration, which is considered to be the best known marker of vitamin $D$ obtained through both diet and body synthesis. According to Holick, the vitamin D level should be higher than $30 \mathrm{ng} / \mathrm{ml}[1]$.

Ethinylestradiol (EE2) is a derivative of $17 \beta$-estradiol (E2), the major endogenous human estrogen. EE2 is used in many forms of combined oral contraception (COC) and is one of the most commonly used medications for this purpose. Ethinylestradiol is hormonally effective by activating the estrogen receptor and thus exerts its estrogenic effects [7].

Drospirenone is a steroidal progestin (of the spironolactone group) used in contraception and hormonal replacement therapy. It is also an aldosterone antagonist with potassium-sparing properties. It is an agonist of the progesterone receptor and an antagonist of the mineralocorticoid and androgen receptors, and hence a progestagen, antimineralocorticoid and antiandrogen. Drospirenone does not present any estrogenic or glucocorticoid or antiglucocorticoid activity. It has a potent antigonadotropic effect at sufficient dosages as a result of progesterone receptor activation. It has been stated that drospirenone has a pharmacological profile that is closely related to that of natural progesterone [8]. Drospirenone is about ten times more potent as an antimineralocorticoid in comparison to spironolactone [8-10]. The drospirenone antimineralocorticoid activity promotes sodium excretion and prevents water retention [10].

It is believed that contraceptives containing estrogens or estrogens combined with progestins may affect $25(\mathrm{OH}) \mathrm{D}$ serum concentrations.

\author{
Corresponding author: \\ Michat Ciebiera MD, PhD \\ First Department \\ of Obstetrics and \\ Gynecology \\ Centre of Postgraduate \\ Medical Education \\ 231 Czerniakowska St \\ 00-416 Warsaw, Poland \\ Phone: +48 607155177 \\ E-mail: michal.ciebiera@ \\ gmail.com
}


There is a lack of reports in this field, but some of them have noted a significant difference in $25(\mathrm{OH}) \mathrm{D}$ concentrations among women using $\mathrm{COC}$ compared to controls. Available literature suggests that the use of COC may have a beneficial effect in increasing $25(\mathrm{OH}) \mathrm{D}$ serum levels, but unfortunately it does not specify the exact composition of the contraceptive pill [11-14]. However, a very recent Turkish study demonstrated that the use of COC in polycystic ovary syndrome (PCOS) patients may decrease $25(\mathrm{OH}) \mathrm{D}$ levels. In the cited study the authors opine that the reason for lower vitamin D concentrations could be related to PCOS or be explained by the low 25(OH)D levels throughout Turkish society, especially in the adult female group [15].

The objective of the study was to investigate the influence of $\mathrm{COC}$ containing EE2 and drospirenone on 25-hydroxyvitamin D serum concentration in women. All patients included in the study provided voluntary informed consent. The patients were recruited in a gynecological clinic from the group of patients without identified chronic diseases during their visits. The sample was limited to premenopausal women who were not pregnant or breastfeeding, had no history of cancer, ovarian removal or hysterectomy, and were not using any form of estrogen and progestin other than the EE2 and drospirenone combined oral pill (in the research group). Selected patients were non-smokers who stated that their diet was healthy and their usual physical activity was normal. Patients were not using any additional dietary supplements. The study included a total of 54 healthy Caucasian woman between 21 and 46 years old from the Mazowieckie and Lubelskie regions in Poland. Twenty-one of them were using combined oral contraception (0.02 or $0.03 \mathrm{mg}$ ethinyloestradiol with $3 \mathrm{mg}$ drospirenone). Patients from the COC group had been using contraception for a minimum of 3 months. In this group the contraception was prescribed for standard registered purposes. Patients from the non-COC group had not used any hormonal form of contraception for at least 3 months. Patients were recruited from September 2014 until May 2015 (not in summer). Standard anthropometric data were obtained from each subject. Weight and height measurements were performed and body mass index (BMI) was calculated for each patient. Venous blood samples were collected from all patients for biochemical analysis. Serum 25(OH)D was measured by a 25(OH)D ELISA kit, Biovendor REA 300/96 (supplied by DLD, Diagnostika GMBH). According to our knowledge the serum level of 25-hydroxyvitamin $D$ is the best indicator of human vitamin D status. An Epoch microplate analyzer (BioTek, USA) was used for
ELISA. Inter- and intra-assay coefficients of variation were $5.1 \%$ and $3.2 \%$, respectively.

The values of the parameters measured on a quotient scale were characterized using mean, median, standard deviation and range of variability. To detect the existence of differences in quantitative traits between the two analyzed groups, Student's $t$-test with the grouping variable was used. The level of $p<0.05$ indicated the existence of a statistically significant dependence or difference. Statistical analysis was performed with Statistica 12.0 software (StatSoft, Poland).

$38.9 \%(n=21)$ of all patients were using the combined oral contraceptive pill and formed the COC research group, while $61.1 \%(n=33)$ were non-COC patients (controls). COC patients' age ranged from 24 to 46 years (half of the patients were older than 35 years - Me = 35); the mean age was $34.48 \pm 7.22$ years. Non-COC patients' age ranged from 21 to 46 years (half of the patients were older than 32 years $-M e=32$ ); the mean age was $33.94 \pm 7.51$ years. The obtained results were statistically insignificant (Student's $t$-test: $t=0.26 ; \mathrm{d} f=52 ; p=0.80)$.

The COC patients' BMI ranged from $18.94 \mathrm{~kg} / \mathrm{m}^{2}$ to $29.39 \mathrm{~kg} / \mathrm{m}^{2}$ (half of the patients had BMI higher than $22.49 \mathrm{~kg} / \mathrm{m}^{2}-\mathrm{Me}=22.49$ ); the mean BMI value was $23.67 \pm 3.42 \mathrm{~kg} / \mathrm{m}^{2}$. Non-COC patients' BMI ranged from $18.38 \mathrm{~kg} / \mathrm{m}^{2}$ to $28.60 \mathrm{~kg} / \mathrm{m}^{2}$ (half of the patients had BMI higher than 22.72 $\mathrm{kg} / \mathrm{m}^{2}-\mathrm{Me}=22.72$ ); the mean BMI value was $23.60 \pm 3.10 \mathrm{~kg} / \mathrm{m}^{2}$. The obtained results were statistically insignificant (Student's $t$-test: $t=0.07$; $\mathrm{d} f=52 ; p=0.94$.

The COC patients' 25(OH)D serum concentrations ranged from $12.02 \mathrm{ng} / \mathrm{ml}$ to $49.78 \mathrm{ng} / \mathrm{ml}$, half of the patients had a $25(\mathrm{OH}) \mathrm{D}$ serum concentration higher than $28.51 \mathrm{ng} / \mathrm{ml}(\mathrm{Me}=28.51)$. Mean 25(OH)D concentration was $30.69 \pm 11.82 \mathrm{ng} / \mathrm{ml}$. Non-COC patients' 25(OH)D serum concentrations ranged from $9.24 \mathrm{ng} / \mathrm{ml}$ to $51.12 \mathrm{ng} / \mathrm{ml}$; half of the controls had a $25(\mathrm{OH}) \mathrm{D}$ serum concentration higher than $18.61 \mathrm{ng} / \mathrm{ml}(\mathrm{Me}=18.61)$. Mean $25(\mathrm{OH}) \mathrm{D}$ concentration was $22.08 \pm 10.54 \mathrm{ng} / \mathrm{ml}$. Comparative analysis demonstrated that mean vitamin D serum concentration differed significantly between groups (Student's $t$-test: $t=2.79 ; \mathrm{d} f=52 ; p=0.007)$. The mean $25(\mathrm{OH}) \mathrm{D}$ serum concentration in women who used $\mathrm{COC}$ was higher than the mean $25(\mathrm{OH}) \mathrm{D}$ serum concentration in controls. Results are presented in Table I and Figure 1.

The majority of available data define vitamin $\mathrm{D}$ insufficiency as 25(OH)D levels of 20-29.9 ng/ml. Deficiency is defined when the level is under $20 \mathrm{ng} / \mathrm{ml}$. An acceptable vitamin D level should be at least $30 \mathrm{ng} / \mathrm{ml}$ [1]. Previous studies have reported that oral contraceptive use can increase $25(\mathrm{OH}) \mathrm{D}$ 
Table I. 25-hydroxyvitamin D serum levels in both groups

\begin{tabular}{|lccc|}
\hline Group & \multicolumn{3}{c|}{ 25-hydroxyvitamin $\mathrm{D}[\mathrm{ng} / \mathrm{ml}]$} \\
\cline { 2 - 4 } & Range & Median & Mean \\
\hline COC & $12.02-49.78$ & 28.51 & $30.69 \pm 11.82$ \\
\hline Non-COC & $9.24-51.12$ & 18.61 & $22.08 \pm 10.54$ \\
\hline P-value & & 0.007 & \\
\hline
\end{tabular}

serum levels. The prevalence of vitamin D deficiency is lower among COC users compared with controls. There is a study that evaluated the relationship between vitamin $\mathrm{D}$ and genetic and environmental determinants. It reported a positive correlation between the use of $\mathrm{COC}$ and higher $25(\mathrm{OH}) \mathrm{D}$ serum levels $[12,13,16]$.

Results obtained in this study suggest that EE2 and drospirenone OC use is associated with higher vitamin $\mathrm{D}$ levels in the healthy patient group. Both groups were very similar and did not differ statistically in age or BMI. The literature is limited in assessment of oral contraception use and vitamin D metabolism. Our findings are similar to the results obtained by other researchers in the past $[12,13]$. Further research is necessary to examine the relationship of the effect of COC on vitamin $\mathrm{D}$ metabolism, as well as the biological cause of this mechanism. It is still unclear whether the type of COC composition changes the $25(\mathrm{OH}) \mathrm{D}$ metabolism.

Our findings are encouraging to conduct further research in this field. The obtained results should be verified in larger groups, and in the case of positive results the next step should be performed with blinded trials. The main task is to investigate which of the $\mathrm{OC}$ components have the major effect on the increase of serum $25(\mathrm{OH}) \mathrm{D}$ level. In the study performed by Schreurs et al. no significant differences were found between the reference group and the group using oral contraceptives with EE2 concentrations of $0.05 \mathrm{mg}$ or $0.03 \mathrm{mg}$ [17]. Because of that, it can be suggested that the $25(\mathrm{OH}) \mathrm{D}$ levels are not influenced by the different estrogenic concentrations. Is therefore drospirenone the component corresponding with increased concentrations of vitamin D? A known fact about vitamin $D$ and the renin-angiotensin-aldosterone system (RAAS) is that VDR complex inhibits renin expression in vitro. It is believed that insufficient vitamin D status is associated with increased renin activity. The proper supplementation of vitamin D can downregulate the RAAS [18-20]. Some of the studies demonstrated an association between vitamin $\mathrm{D}$ metabolites and components of the RAAS. 25(OH)D levels inversely correlate with renin activity in plasma as well as with elevated circulating levels of angiotensin II

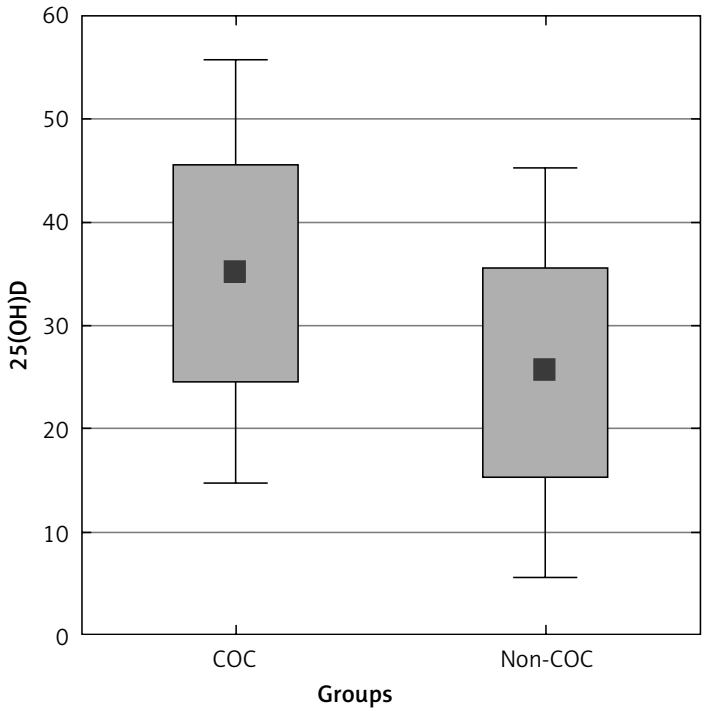

Figure 1. 25-hydroxyvitamin D serum levels in both groups

[18-20]. Some data suggest that angiotensin II may have an effect on osteoblastic differentiation and expression of osteogenesis-related transcription factors [21]. There are also studies about the effect of spironolactone on improving vitamin D metabolism (changes in kidney gene expression) [22]. Drospirenone-associated metabolic pathways affecting vitamin $D$ metabolism require additional studies. While the pharmaceutical market is receiving a new form of contraception based only on drospirenone, it may be interesting that apart from the other advantages, it may also have a beneficial effect on patients' vitamin $D$ status [23] and be a suitable OC option in 25(OH)D insufficient patients. According to our latest results, if drospirenone contraception were proven to raise the vitamin $D$ serum level, this could also be a good choice for patients at high risk of uterine fibroids [24, 25].

The main conclusion of this study is that the use of COC increases the circulating levels of $25(\mathrm{OH}) \mathrm{D}$ in premenopausal, healthy, adult women. This is the first study revealing the potential effect of $\mathrm{COC}$ with EE2 and drospirenone on the serum $25(\mathrm{OH}) \mathrm{D}$ levels in women. In our data this form of contraception increased circulating $25(\mathrm{OH})$ levels. Therefore this COC can also be considered in some groups of patients as a potential addition to vitamin D supplementation in the deficiency group or in the deficiency high risk group. Further research on larger groups is necessary to determine the exact role of both EE2 and drospirenone in vitamin $\mathrm{D}$ metabolism. A properly constructed randomized control trial would answer most of the unknown aspects.

All of the STROBE guidelines were indicated in the preparation of this manuscript. 


\section{Conflict of interest}

The authors declare no conflict of interest.

\section{References}

1. Holick MF. Vitamin D deficiency. N Engl J Med 2007; 357: 266-81.

2. Holick MF. Vitamin D: importance in the prevention of cancers, type 1 diabetes, heart disease, and osteoporosis. Am J Clin Nutr 2004; 79: 362-71.

3. Pelczyńska M, Grzelak T, Sperling M, Bogdański P, Pupek-Musialik D, Czyżewska K. Impact of 25-hydroxyvitamin $D$, free and bioavailable fractions of vitamin $D$, and vitamin $\mathrm{D}$ binding protein levels on metabolic syndrome components. Arch Med Sci 2017; 13: 745-52.

4. Brannon PM, Yetley EA, Bailey RL, Picciano MF. Overview of the conference "Vitamin D and Health in the 21st century: an update". Am J Clin Nutr 2008; 88: 483S-90S.

5. Pludowski P, Holick MF, Pilz S, et al. Vitamin D effects on musculoskeletal health, immunity, autoimmunity, cardiovascular disease, cancer, fertility, pregnancy, dementia and mortality - a review of recent evidence. Autoimmun Rev 2013; 12: 976-89.

6. Krela-Kaźmierczak I, Szymczak A, Łykowska-Szuber L, et al. The importance of vitamin $D$ in the pathology of bone metabolism in inflammatory bowel diseases. Arch Med Sci 2015; 11: 1028-32.

7. Evans G, Sutton EL. Oral contraception. Med Clin North Am 2015; 99: 479-503.

8. Muhn P, Fuhrmann U, Fritzemeier KH, Krattenmacher R, Schillinger E. Drospirenone: a novel progestogen with antimineralocorticoid and antiandrogenic activity. Ann N Y Acad Sci 1995; 761: 311-35.

9. Fuhrmann U, Krattenmacher R, Slater EP, Fritzemeier $\mathrm{KH}$. The novel progestin drospirenone and its natural counterpart progesterone: biochemical profile and antiandrogenic potential. Contraception 1996; 54: 243-51.

10. Genazzani AR, Mannella P, Simoncini T. Drospirenone and its antialdosterone properties. Climacteric 2007; 10 (Suppl. 1): 11-8.

11. Sowers M, Wallace R, Hollis B, Lemke JH. Parameters related to $25-\mathrm{OH}-\mathrm{D}$ levels in a population-based study of women. Am J Clin Nutr 1986; 43: 621-8.

12. Harris SS, Dawson-Hughes B. The association of oral contraceptive use with plasma 25-hydroxyvitamin D levels. J Am Coll Nutr 1998; 17: 282-4.

13. Brinker KA. Oral contraceptive use and vitamin D status among women ages 15-44 in the US: a cross-sectional study. 2012. http://pid.emory.edu/ark:/25593/brdcm (online 24.09.2016)

14. Adami S, Bertoldo F, Braga V, et al. 25-hydroxyvitamin D levels in healthy premenopausal women: association with bone turnover markers and bone mineral density. Bone 2009; 45: 423-6.

15. Namli Kalem M, Hizli D, Kamalak Z, et al. Effect of combined oral contraceptive use on serum 25-hydroxyvitamin D levels and ultrasound parameters in patients with polycystic ovary syndrome. Gynecol Endocrinol 2016; 32: 281-4.

16. Viragh E, Horvath D, Locsei Z, et al. Vitamin D supply among healthy blood donors in Vas County, Hungary. Orv Hetil 2012; 154: 1629-37.

17. Schreurs WH, van Rijn HJ, van den Berg H. Serum 25-hydroxycholecalciferol levels in women using oral contraceptives. Contraception 1981; 23: 399-406.
18. Li YC, Kong J, Wei M, Chen ZF, Liu SQ, Cao LP. 1,25-Dihydroxyvitamin $D(3)$ is a negative endocrine regulator of the renin-angiotensin system. J Clin Invest 2002; 110: 229-38.

19. Vaidya A, Forman JP, Hopkins PN, Seely EW, Williams JS. 25 -Hydroxyvitamin $D$ is associated with plasma renin activity and the pressor response to dietary sodium intake in Caucasians. J Renin Angiotensin Aldosterone Syst 2011; 12: 311-9.

20. Brown J, Vaidya A. Interactions between adrenal and calcium-regulatory hormones in human health. Curr Opin Endocrinol Diabetes Obes 2014; 21: 193-201.

21. Nakai K, Kawato T, Morita T, et al. Angiotensin II suppresses osteoblastic differentiation and mineralized nodule formation via AT1 receptor in ROS17/2.8 cells. Arch Med Sci 2015; 11: 628-37.

22. Alesutan I, Feger M, Pakladok T, et al. 25-Hydroxyvitamin D3 1-alpha hydroxylase-dependent stimulation of renal Klotho expression by spironolactone. Kidney Blood Press Res 2013; 37: 475-87.

23. Archer DF, Ahrendt HJ, Drouin D. Drospirenone - only oral contraceptive: results from a multicenter noncomparative trial of efficacy, safety and tolerability. Contraception 2015; 92: 439-44.

24. Brakta S, Diamond JS, Al-Hendy A, Diamond MP, Halder SK. The role of vitamin $D$ in uterine fibroid biology. Fertil Steril 2015; 104: 698-706.

25. Ciebiera M, Włodarczyk M, Słabuszewska-Jóźwiak A, Nowicka G, Jakiel G. Influence of vitamin D and transforming growth factor beta3 serum concentrations, obesity, and family history on the risk for uterine fibroids. Fertil Steril 2016; 106: 1787-92. 